\title{
Effect of Carburizing and Nitriding on Fatigue Properties of 18Cr2Ni4WA Steel in Very High Cycle Fatigue Regime
}

\author{
Zhenduo Sun ${ }^{1 *}$, Dongbo Hou ${ }^{1}$, Wei $\mathrm{Li}^{2}$ \\ ${ }^{1}$ Hebei University, School of Quality and Technical Supervision, Baoding 071000, China \\ ${ }^{2}$ School of Mechanical Engineering, Beijing Institute of Technology, Beijing 100081, China
}

Corresponding Author Email: bdsunzhenduo@126.com

https://doi.org/10.18280/acsm.450303

Received: 17 January 2021

Accepted: 20 March 2021

\section{Keywords:}

very high cycle fatigue, carburizing, nitriding, inclusion, defect, life prediction

\begin{abstract}
The work aims to study the influence of carburizing and nitriding on fatigue properties of $18 \mathrm{Cr} 2 \mathrm{Ni} 4 \mathrm{WA}$ high strength steel in very high cycle fatigue regime. Very high cycle fatigue tests were carried out on 18Cr2Ni4WA Steel after carburizing and nitriding respectively. The micro morphology of fatigue fracture was observed by scanning electron microscope, the failure mode and failure mechanism were discussed. The relationship between fatigue life and defect size, FGA size, fish eye size of fracture was analyzed. The characteristic size of defects is evaluated by Gumbel, Weibull and GEV distribution functions, and a modified Akiniwa fatigue life prediction model considering the relationship between FGA size and inclusion size was established. The results showed that, nitriding and carburizing treatment improve the surface fatigue limit of the steel. The fatigue life decreases with the increase of internal defect size and FGA size. After carburizing and nitriding treatment, the internal fatigue strength of the specimen decreases slightly. When the failure probability is $99 \%$, the internal defect sizes of nitrided specimens calculated by Weibull, Gumbel and GEV distributions are $141.5 \mu \mathrm{m}$, $148.4 \mu \mathrm{m}$ and $211.7 \mu \mathrm{m}$ respectively. The calculated internal defect sizes of carburized specimens are $47 \mu \mathrm{m}, 67.8 \mu \mathrm{m}$ and $40 \mu \mathrm{m}$ respectively. Compared with the experimental data, the fatigue strength predicted by GEV is the most appropriate. carburizing and nitriding treatment can improve the surface fatigue strength of $18 \mathrm{Cr} 2 \mathrm{Ni} 4 \mathrm{WA}$ steel, but slightly reduce the internal fatigue strength. The prediction result of the new model is conservative when the failure probability is $99 \%$, which is suitable for engineering application.
\end{abstract}

\section{INTRODUCTION}

In the era of rapid development of high-speed railway, automobile and other products, its key parts or components need to withstand high speed, heavy load and other operating conditions, therefore, high strength alloy steels is more and more widely used in the manufacturing of these components [1-4]. In addition, many key parts or components need to withstand very high cycle life ( $>10^{7}$ cycles) without failure. Therefore, the study on very high cycle fatigue (VHCF) of high strength alloy steels has been a focus.

Surface strengthening can significantly improve the surface fatigue strength, but surface strengthening doesn't significantly improve the internal fatigue performance [5-7]. In order to improve very high cycle fatigue performance of high strength steel, surface strengthening methods are usually used such as carburizing, nitriding or shot peening [8-10]. After surface strengthening, compression residual stress is generated on the surface of parts, and tensile residual stress is generated in the internal matrix. The residual stress affects the distribution of stress under cyclic load, thus leading to the reduction of tensile stress. Therefore, surface strengthening can only promote the fatigue strength of surface failure specimens [11]. Limodin et al. [12] studied the fatigue failure mechanism of AISI4140 steel after nitridation, and found that if the stress amplitude is high enough to cause surface crack initiation, surface strengthening can increase the fatigue life of smooth specimen, while surface strengthening has little effect on the internal fatigue life within the long fatigue life range where internal crack initiation occurs. Chen et al. [13] studied the fatigue properties of carburized and nitrided 20CrMo low carbon alloy steels and believed that, compared with carburized steel, the wear resistance of the specimens after nitrided steel was nearly doubled, the gear deformation was smaller and the toughness of the workpiece was better. Mayer et al. [7] studied the very high cycle fatigue properties of $18 \mathrm{Ni}$ maraging steel sheet with surface nitrided under $10^{7}$ to $10^{9}$ very high cycle fatigue cycles, and believed that the fatigue cracks only started at the internal inclusions, the surface hardening lost its initial effect, and had no effect on the specimen interior-induced fatigue failure. Song et al. [14] analyzed the fracture characteristics under very high cycle fatigue, and based on the surface crack propagation and dislocation theory, established a fatigue life prediction model in which the crack source originated from the competitive mechanism between surface and internal. Sun et al. [15] analyzed the "fisheye" characteristics in the fracture of very high cycle fatigue failure specimens, and considered the dual effects of inclusion size and fine granular area (FGA) size on crack growth, and proposed a model to predict the fatigue life of fisheye type failure high-strength steel under very high cycle fatigue cycle. However, due to the uncertainty of the 
fatigue life range of FGA, the prediction model has great limitations. Xie et al. [16] added Paris formula to Tanaka and Murakami's model and established a prediction model for very high cycle fatigue life of metallic materials when cracks were generated near surface inclusions. Moreover, this model has a few material-dependent parameters and requires a large amount of experimental data for parameter correction. These results indicate that surface strengthening changes the surface hardness, internal microstructure and residual stress of the material, and promotes the surface fatigue life and fatigue limit of the material to a certain extent. However, in the VHCF regime, the effect of surface strengthening on the properties of the internal failure specimens is not clear. Therefore, it is of great significance to consider the influence of the size of internal defects on VHCF life of high strength steel.

In this study, the axial loading experimentals of carburized and nitrided $18 \mathrm{Ni} 2 \mathrm{Cr} 4 \mathrm{WA}$ steel were carried out, and discuss the effects of carburizing and nitriding on their fatigue properties. A new model for predicting the very high cycle fatigue life of $18 \mathrm{Ni} 2 \mathrm{Cr} 4 \mathrm{WA}$ steel was established. Gumbel distribution [17], Weibull distribution [18] and GEV distribution [19] were used to calculate the internal defect size of $18 \mathrm{Ni2Cr} 4 \mathrm{WA}$ steel. Using the calculation formula of internal crack growth and the $S-N$ (stress-number of cycles) experimental data of carburized and nitrided specimens, combined with the Murakami model and Paris law, the applicability of using statistical methods to estimate the maximum defect size to predict fatigue life was further explored. In the present study, more surface strengthening techniques are needed for further development.

\section{EXPERIMENTAL PROCEDURES}

\subsection{Material and specimen}

The Material investigated in this study is a high strength $18 \mathrm{Cr} 2 \mathrm{Ni} 4 \mathrm{WA}$ steel, its main chemical composition (mass percentage) is shown in Table 1.

The specimen shape is shown in Figure 1. The total number of specimens was 50, of which 11 were treated with nitriding, 14 with carburized and 25 with basic heat treatment.

Table 1. Chemical composition of $18 \mathrm{Cr} 2 \mathrm{Ni} 4 \mathrm{WA}$ steel (wt. \%)

\begin{tabular}{ccccccc}
\hline $\mathbf{C}$ & $\mathbf{S i}$ & $\mathbf{M n}$ & $\mathbf{C r}$ & $\mathbf{N i}$ & $\mathbf{W}$ & $\mathbf{V}$ \\
\hline 0.16 & 0.19 & 0.33 & 1.55 & 4.22 & 0.97 & 0.01 \\
\hline
\end{tabular}

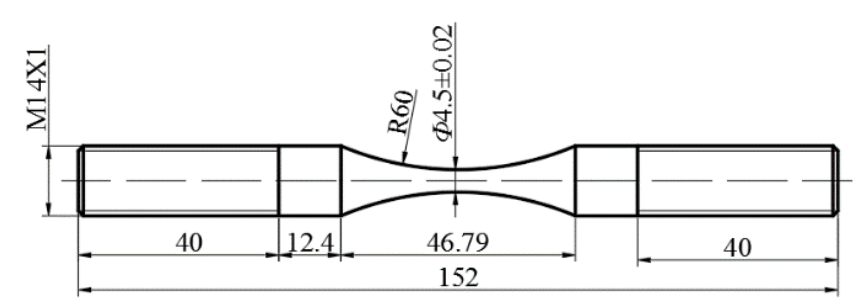

Figure 1. Shape and dimensions of specimen (units: $\mathrm{mm}$ )

\subsection{Carburizing and nitriding process}

Carburizing treatment: Carburizing in vacuum furnace at $950^{\circ} \mathrm{C}$ for $8 \mathrm{~h}$; and then quenching in oil after furnace temperature is reduced to $860^{\circ} \mathrm{C}$ for half an hour, air cooling; finally tempering at $170^{\circ} \mathrm{C}$ for $3 \mathrm{~h}$, air cooling. These specimens are called Carburized specimens (CS), and the expected depth of carburizing layer is about $0.8-1.2 \mathrm{~mm}$. Nitriding treatment: Nitriding furnace temperature first rises up to $530^{\circ} \mathrm{C}$, and then is held for $16 \mathrm{~h}$, air cooling; quenching in oil at $850^{\circ} \mathrm{C}$ for $1 \mathrm{~h}$, air cooling; finally tempering at $525^{\circ} \mathrm{C}$ for $2 \mathrm{~h}$, air cooling. These specimens are called Nitriding specimens (NS). Basic heat treatment: tempering at $840^{\circ} \mathrm{C}$ for half an hour and tempering at $170^{\circ} \mathrm{C}$ after oil quenching for 3 h. These specimens are called Untreated specimens (US). After heat treatment, 240 to 2000 abrasive paper is used to grind the middle part of all specimens in a direction parallel to the specimen axis to final shapes.

\subsection{Microscopic observation}

After etching in 4\% alcohol nitric acid solution, the crosssectional microstructure of carburized and nitrided specimens observed by using the scanning electron microscopy (SEM) is shown in Figures 2 and 3. The fracture cross section of the NS and CS was observed under low power microscope. The fracture is divided into outer hardened layer and inner matrix. An obvious boundary can be observed between the hardened layer and the matrix area of CS, as shown in Figure 2(a), while the boundary of NS is not obvious but can be roughly distinguished, as shown in Figure 3(a). The hardened layer of the carburized specimen contains high carbon tempered martensite and residual austenite, as shown in Figure 2(b), and low carbon tempered martensite can be observed in the matrix, as shown in Figure 2(c). For nitrided specimens, it is found in Figure 3(b) and (c) that there is obvious white nitrite in the hardened layer, and the matrix area contains residual austenite and bainite.

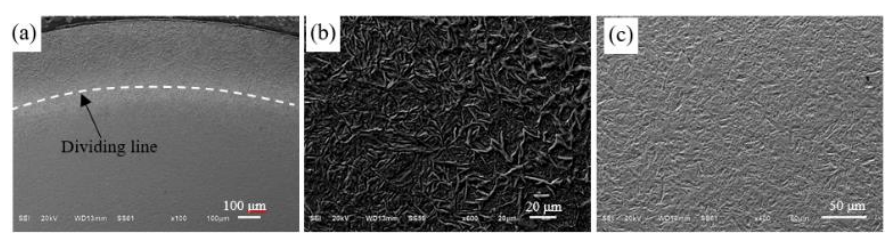

Figure 2. Microstructure of CS

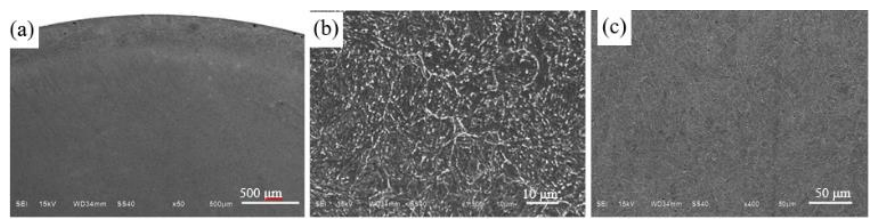

Figure 3. Microstructure of NS

\subsection{Fatigue experimentaling method}

Very high cycle fatigue experimentals under axial tensioncompression loading were carried out on three kinds of specimens using QBG-100 high frequency fatigue experimentaling machine with a frequency of $100 \mathrm{~Hz}$ in the life range of $10^{4}-10^{9}$ cycles with the constant stress ratio of -1 . Fatigue experimentals are carried out in an open environment and at room temperature. After the experiment, the fracture was observed by SEM and the dimensions of inhomogenous matrix area (IMA), FGA and fisheye were measured by Image J software. 


\section{RESULTS AND DISCUSSION}

\subsection{Micro-hardness}

Agilent-G200 nano-indentation instrument was used to measure the microhardness of carburized and nitrided specimens along the direction from the surface to the center of the polished specimens. The results show that the maximum hardness appears near the surface of the specimens after carburization and nitridation, the value of which is $1000 \mathrm{HV}$ and $800 \mathrm{HV}$, respectively. Moreover, the hardness values of both are distributed in a gradient, and gradually decrease from the surface to the inside, and finally reaches a constant value of $500 \mathrm{HV}$ a the depth exceeds the hardened layer, as shown in Figure 4. Furthermore, $500 \mathrm{HV}$ is similar with the microhardness of the US material. Apparently, it can be proven that the depth of the carburized layer and nitrided layer are about $900 \mu \mathrm{m}$ and $280 \mu \mathrm{m}$ respectively.

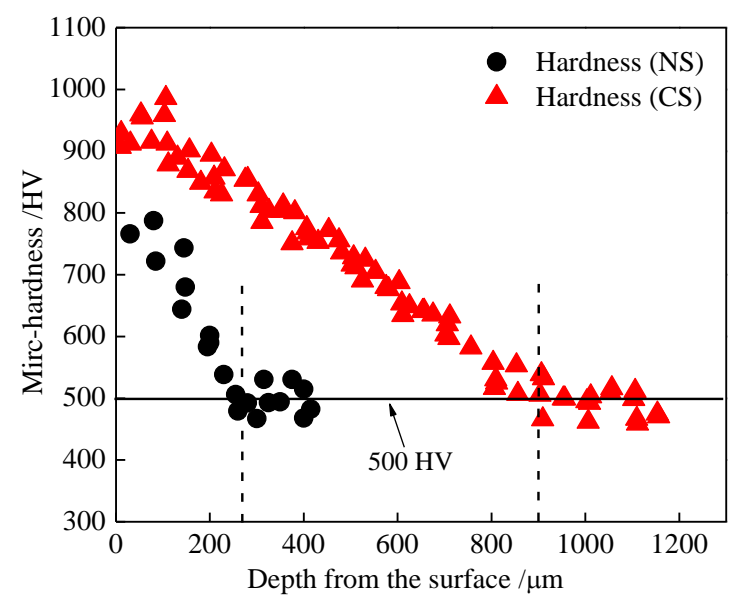

Figure 4. Hardness distribution of $\mathrm{CS}$ and $\mathrm{N}$

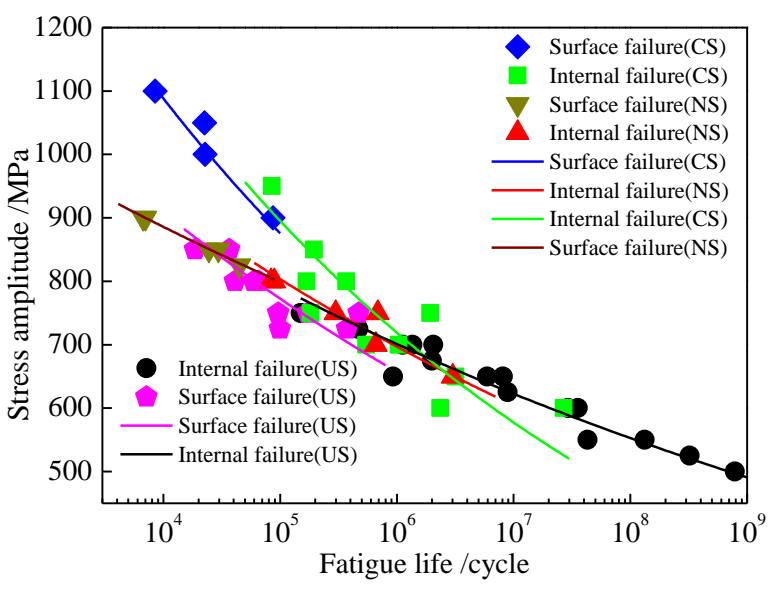

Figure 5. $S-N$ curve

\section{2 $S-N$ characteristics}

The $S-N$ diagram obtained from the $18 \mathrm{Cr} 2 \mathrm{Ni} 4 \mathrm{WA}$ steel under the life range of $10^{4}-10^{9}$ cycles is shown in Figure 5 . According to the SEM observation of fracture surface and the preliminary observation of crack initiation sites, the fatigue failure of the three specimens can be divided into two modes: surface-induced failure and interior-induced failure. The surface failure mainly occurred in the high stress zone $\left(\sigma_{a}>\right.$ $700 \mathrm{MPa})$ with short fatigue life $\left(<10^{5}\right.$ cycles $)$, while the internal failure mainly occurred in the low stress zone $\left(\sigma_{a}<\right.$ $700 \mathrm{MPa}$ ) with long fatigue life ( $>10^{5}$ cycles $)$. It is obvious that internal failure is the main failure mode of the three specimens within the long fatigue life range of $N>10^{7}$ cycles. The specimens of $18 \mathrm{Cr} 2 \mathrm{Ni} 4 \mathrm{Wa}$ steel show the $S-N$ characteristics of decreasing continuously when the stress ratio is -1 .

According to the observation of the $S-N$ curve of the specimens with surface failure, the nitrided and carburized specimens $S-N$ data exhibit the linearly descending trend without fatigue limit around $10^{7}$ cycles, and the surface failure occurs when the stress amplitude exceeds $840 \mathrm{MPa}$ and $900 \mathrm{MPa}$, while the US have surface failure fatigue limit about $740 \mathrm{MPa}$. Compared with the US, the surface failure fatigue strength of NS and CS is increased by $13.5 \%$ and $21.6 \%$, respectively. For the internal failure specimens, there is no fatigue limit and they all show a continuous decline of $S-N$ characteristics. In addition, the decline rate of the CS is greater than that of the NS. Under relatively low load conditions, the surface crack initiation is inhibited by the existence of hardened layer and surface residual compression stress, so that internal failure is more likely to occur.

On the other hand, under a certain low stress amplitude (about $\sigma_{a}<700 \mathrm{MPa}$ ), the fatigue life of the NS and CS is lower than that of the US, which is mainly attributed to the tensile residual stress in the specimen matrix area caused by the action of carburizing and nitriding. This phenomenon indicates that the surface treatment technology can inhibit the fatigue life and fatigue limit of the material internal failure under the very high cycle fatigue life cycle. This result is similar to some results of the deterioration of fatigue properties caused by the tensile residual stress under the very high cycle fatigue life cycle due to shot peening treatment [6].

\subsection{Observation of fracture surfaces}

Fatigue failure of nitriding and carburizing specimens can be induced by surface or internal failure. For surface failure specimens, the fracture morphology of nitrided and carburized specimens can be divided into crack initiation zone, propagation zone and transient fracture zone. In the beginning, the initiation of fatigue crack is caused by the weak surface finishing defect, as shown in Figure 6(a) and Figure 7(a), and then the crack continues to expand from the surface defect until the instability and fatigue fracture. For the internal failure specimens, the 'fisheye' centered on the crack source can be observed in the fracture center area of both carburizing and nitriding specimens, as shown in Figure 6(d) and Figure 7(d). There are two types of crack sources, one is non-uniform matrix structure, the other is non-metallic inclusion, as shown in Figure 6(b), (c) and Figure 7(b), (c). And the crack source formation is limited to the matrix region, because the high hardness of the hardened layer inhibits the surface crack source initiation.

The size of crack source is different under nitriding and carburizing treatments. The size range of crack source of nitrided specimens is 14.7-76.86 $\mu \mathrm{m}$, and its average size is $43.5 \mu \mathrm{m}$, the fisheye size of it ranges from 481.9-1545.4 $\mu \mathrm{m}$, with an average size of $958.2 \mu \mathrm{m}$. For carburized specimens, the crack source size ranges from $18.9 \mu \mathrm{m}$ to $44.3 \mu \mathrm{m}$ with an average size of $27.9 \mu \mathrm{m}$, and the fisheye size ranges from $142.5 \mu \mathrm{m}$ to $2227.6 \mu \mathrm{m}$ with an average size of $1427.2 \mu \mathrm{m}$. The size of defects in the specimens after nitridation is obviously larger than that after carburization. Based on this, it can be concluded that carburizing treatment is better than 
nitriding treatment in inhibiting the formation of large-size defects. The fisheye size is related to the location of the crack source because the crack ends when it diffused into the hardened layer, as shown in Figure 6(d) and Figure 7(d). This means that the fisheye size formed from the crack source in the center of the matrix is generally longer than that near the hardened layer. The fisheye size of the nitrided specimen is smaller than that of the carburized specimen, which may be due to the higher hardness of the carburized layer, which promotes the generation of the crack source at the center of the matrix. However, the relationship between the fisheye size and the fatigue life is not clear yet, and further research is needed.
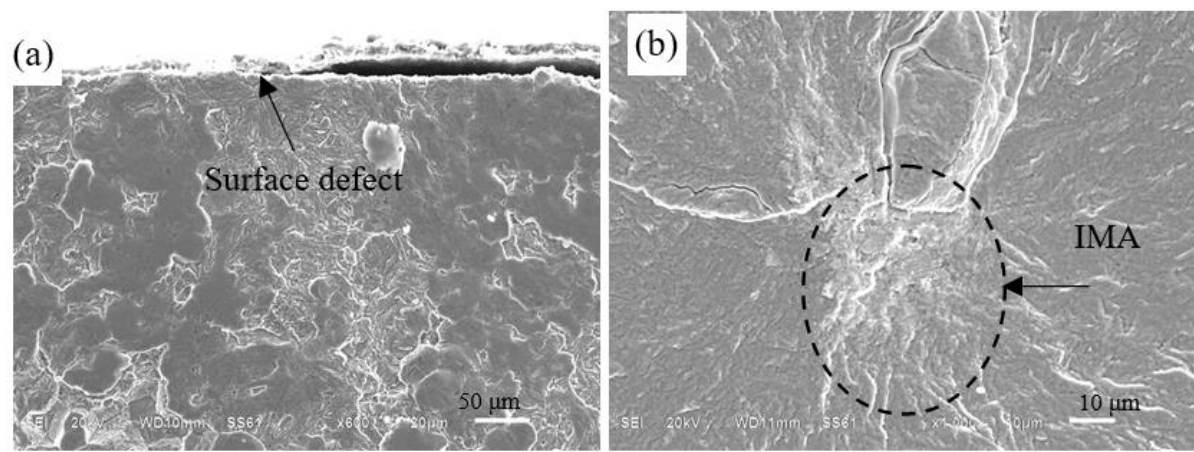

(a) Surface defect $\left(\sigma_{\mathrm{a}}=1000 \mathrm{MPa}, \mathrm{N}_{\mathrm{f}}=22700\right)$; (b) IMA $\left(\sigma_{\mathrm{a}}=750 \mathrm{MPa}, \mathrm{N}_{\mathrm{f}}=1936800\right)$
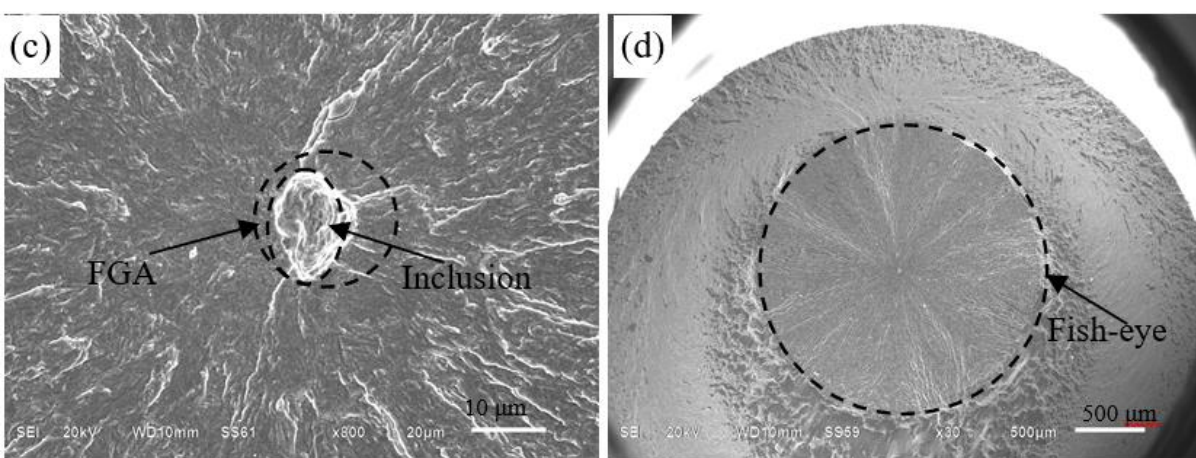

(c) Inclusion and FGA $\left(\sigma_{\mathrm{a}}=650 \mathrm{MPa}, N_{\mathrm{f}}=3174000\right)$; (d) Fish-eye $\left(\sigma_{\mathrm{a}}=650 \mathrm{MPa}, N_{\mathrm{f}}=3174000\right)$

Figure 6. Observation of CS fracture surface
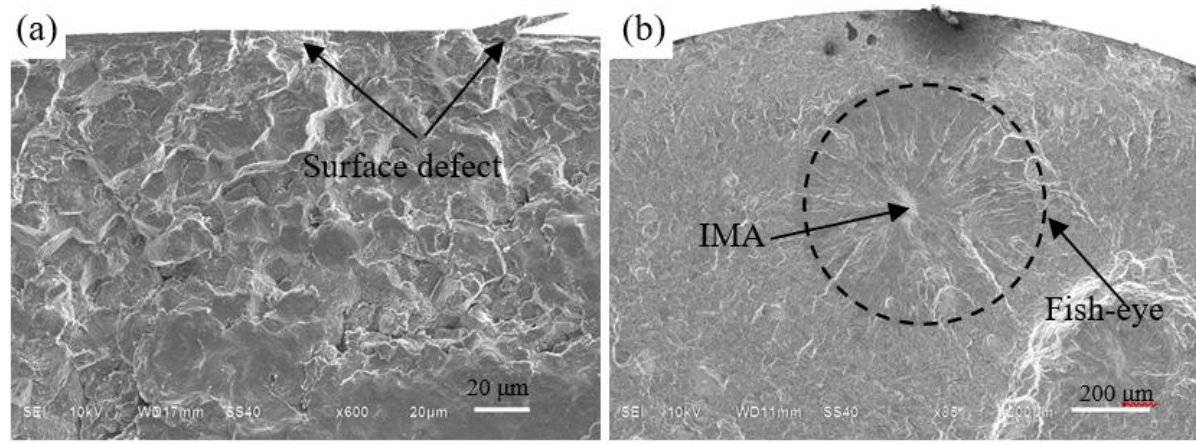

(a) Surface defect $\left(\sigma_{\mathrm{a}}=900 \mathrm{MPa}, N_{\mathrm{f}}=6700\right)$; (b) IMA and fish-eye $\left(\sigma_{\mathrm{a}}=700 \mathrm{MPa}, N_{\mathrm{f}}=662500\right)$
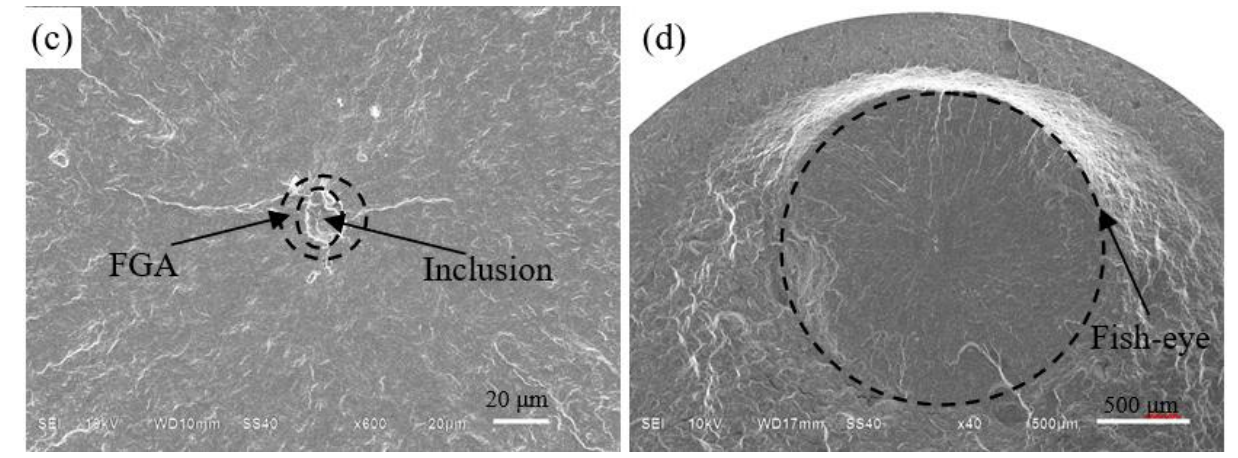

(c) Inclusion and FGA $\left(\sigma_{\mathrm{a}}=650 \mathrm{MPa}, N_{\mathrm{f}}=3011400\right)$; (d) Fish-eye $\left(\sigma_{\mathrm{a}}=800 \mathrm{MPa}, N_{\mathrm{f}}=89200\right)$

Figure 7. Observation of NS fracture surface 


\section{FATIGUE LIFE PREDICTION}

\subsection{Evaluation of stress intensity factor}

Based on the fractography, internal inclusions and heterogeneous matrix structures are collectively referred to as internal defects, whose shape is considered to be round, and $r_{\text {def }}$ is defined as the radius of internal defects. In addition, the parameter $\sqrt{\text { area }}$ denotes the size of defect or crack, evaluated by the square root of its area. $\sqrt{\text { area }_{\text {def }}}$ represents the size of the internal defect.

The size of internal defects is small, equivalent to small cracks. Based on the model proposed by Murakami [18], the stress intensity factor of internal defects is:

$$
\Delta K_{\mathrm{def}}=0.5 \Delta \sigma \sqrt{\pi \sqrt{\text { area }_{\mathrm{def}}}}
$$

where, $\Delta \sigma$ is stress range. Herein, Since the stress ratio $R=-1$ and the tension is the main factor affecting the crack growth in monotonic tension test, Therefore, the stress range $\Delta \sigma$ in Eq. (1) can be replaced by $\sigma_{a}$, and then the value of $\Delta \mathrm{K}_{\text {def }}$ in Eq. (1) can be given by:

$$
\Delta K_{\mathrm{def}}=0.5 \sigma_{a} \sqrt{\pi \sqrt{\text { area }_{\mathrm{def}}}}
$$

Considering the failure mechanism of high strength steel, Tanaka and Akiniwa [20] and Akiniwa et al. [21] defined inclusion size as crack size. The crack initiation and initial propagation zone follow the Paris formula, and the growth rate $\left(d_{a} / d_{N}\right)_{\text {int }}$ of internal crack can be described by the Paris law:

$$
\left(d_{a} / d_{N}\right)_{\mathrm{int}}=C(\Delta K)^{m}
$$

where, $\mathrm{C}$ and $m$ are constants related to the material.

About $90 \%$ of the fatigue life of the internal failure specimen is used to form FGA or fisheye, so the formation life of FGA or fisheye is equivalent to the fatigue life. By combining Eqns. (2) and (3), the relationship between fatigue life and stress intensity factor can be obtained through power law integration:

$$
\left(\Delta K_{\text {def }}\right)^{m}\left(\frac{N_{f}}{\sqrt{\text { area }_{\text {def }}}}\right)=\frac{2}{C(m-2)}\left[1-\left(\frac{\sqrt{\text { rrea }_{\text {def }}}}{\sqrt{\text { area }_{F G A}}}\right)^{(m-2) / 2}\right]
$$

The relationship between $\Delta K_{\text {def }}, \Delta K_{\mathrm{FGA}}$ and $\Delta K_{\text {fisheye }}$ of nitrided and carburized specimens and fatigue life is shown in Figure 8 . First of all, $\Delta K_{\text {def }}$ shows a decreasing trend with the increase of fatigue life, as shown by the solid red and black lines in Figure 8 . The $\Delta K_{\text {def }}$ value of the carburized specimen is in the range of $2.4-4.4 \mathrm{MPa} \cdot \mathrm{m}^{1 / 2}$, and the $\Delta K_{\text {def }}$ value of the nitrided specimen is in the range of 2.2-6.2 $\mathrm{MPa} \cdot \mathrm{m}^{1 / 2}$, which is greater than that of the carburized specimen, indicating that the effect of carburized treatment in preventing crack growth is better than that of the nitrided treatment. On the other hand, the value of carburizing and nitriding specimens $\Delta K_{\mathrm{FGA}}$ is between 3.5-3.9 MPa $\cdot \mathrm{m}^{1 / 2}$, which tends to be a constant value of $3.71 \mathrm{MPa} \cdot \mathrm{m}^{1 / 2}$ regardless of nitriding or carburizing treatment, and does not change with the change of fatigue life. Carburizing treatment $\Delta K_{\mathrm{FGA}}$ value is greater than nitriding treatment. In addition, under certain fatigue life, the value of $\Delta K_{\mathrm{FGA}}$ is greater than that of $\Delta K_{\text {def }}$ when FGA can be observed near the internal defect. Therefore, when FGA is produced, the maximum value of $\Delta K_{\text {def }}$ is $3.71 \mathrm{MPa} \cdot \mathrm{m}^{1 / 2}$.

The $\Delta K_{\text {fisheye }}$ values of carburized and nitrided specimens are in the range of 17.2-32.9 $\mathrm{MPa} \cdot \mathrm{m}^{1 / 2}$ and $14.5-27.9 \mathrm{MPa} \cdot \mathrm{m}^{1 / 2}$, respectively, and their average values are $19 \mathrm{MPa} \cdot \mathrm{m}^{1 / 2}$ and 20 $\mathrm{MPa} \cdot \mathrm{m}^{1 / 2}$, respectively, with little difference between them. It can be seen from Figure 8 that the value of $\Delta K_{\text {fisheye }}$ has little relationship with fatigue life and tends to a constant value of 18.22 $\mathrm{MPa} \cdot \mathrm{m}^{1 / 2}$. Combined with previous studies [22, 23], the formation of fisheye means the end of the early crack and the crack begins to grow in an unstable manner. Therefore, $\Delta K_{\text {fisheye }}$ is the threshold to control the unstable growth of the inner long crack. This means that after the formation of a fisheye, even if the applied load remains constant, the fatigue crack growth rate will suddenly accelerate.

Figure 9 shows the relationship between $\Delta K_{\text {def }}$ and $\frac{N_{f}}{\left(\sqrt{\text { are } a_{\mathrm{def}}}\right)^{1 / 2}}$. By using the least square method, the relationship between the two is represented by the black line and the red line in Figure 9. Based on the formula transformation, the values of parameter $C$ and $m$ can be determined. In addition, it needs to be pointed out that in this paper, the logarithmic coordinates are adopted in the process of fitting calculation, and the unit of $\mathrm{d} a / \mathrm{d} N$ is $\mathrm{m} \cdot$ cycle $^{-1}$ and the unit of $\Delta K$ is $\mathrm{MPa} \cdot \mathrm{m}^{1 / 2}$. Later, parameters in relevant literatures and standards are also quoted based on this set of units.

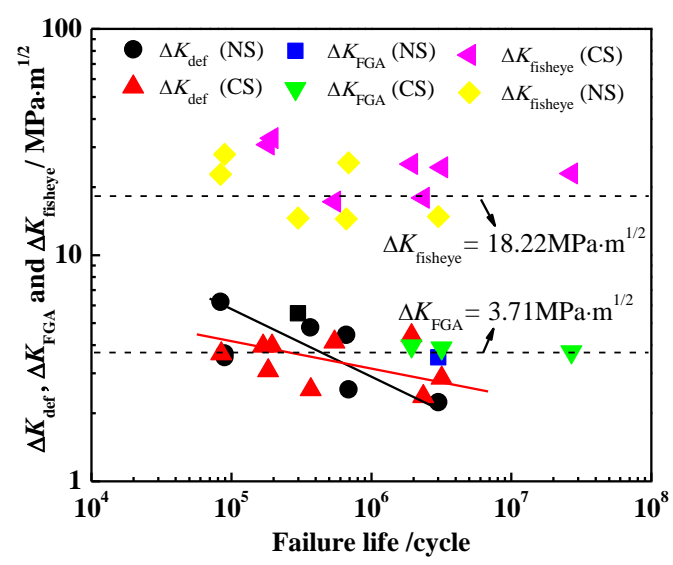

Figure 8. Relationship between $\Delta k_{\mathrm{def}}, \Delta k_{\mathrm{FGA}}$ and fatigue life

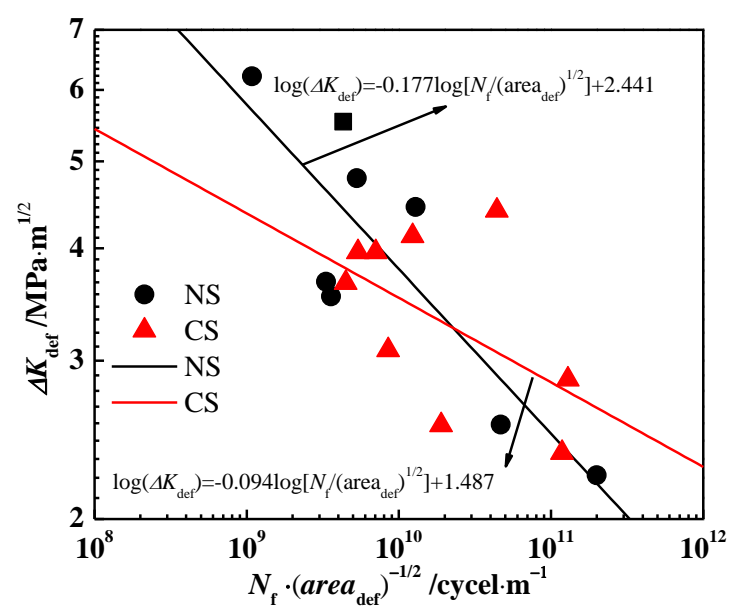

Figure 9. Relationship between $\Delta k_{\text {def }}$ and $N_{\mathrm{f}} /\left(\text { are } a_{\text {def }}\right)^{1 / 2}$ 


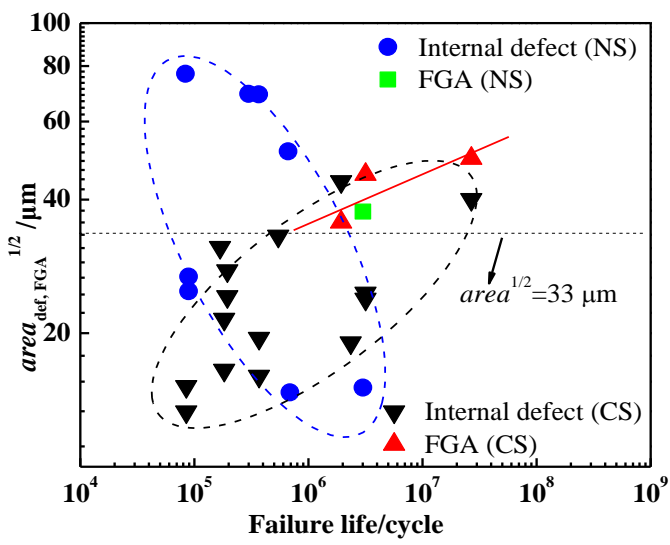

Figure 10. Relationship between $\sqrt{\text { area }_{\mathrm{def}}}, \sqrt{\text { area }_{F G A}}$ and $N_{f}$

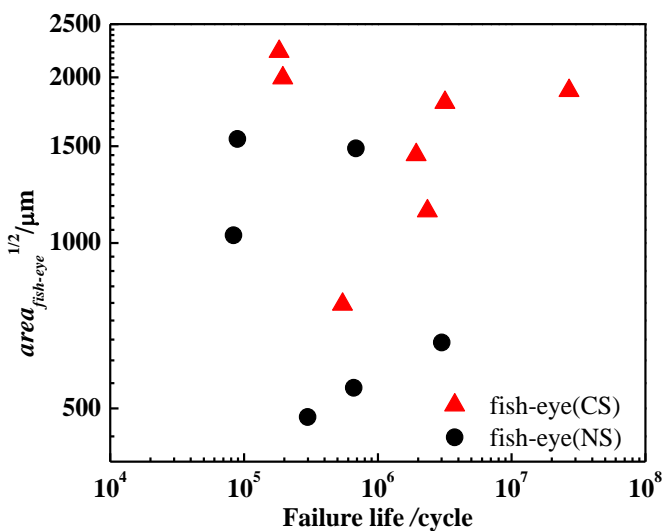

Figure 11. Relationship between $\sqrt{\operatorname{area}_{\text {fish-eye }}}$ and $N_{f}$

\subsection{Statistical evaluation of defect sizes}

Internal defects such as the largest non-metallic inclusion in the specimen are the main reasons for internal failure. The relationship between the size of internal defects, FGA and fatigue life is shown in Figure 10. The size of internal defects and FGA in the carburized specimen can be divided by the virtual straight line in the figure, and the fatigue life increases with the increase of defect size and FGA, as shown in the black dotted box and red straight line in Figure 10. The fatigue life of nitriding specimens shows a downward trend with the increase of the size of internal defects, as shown in the blue dotted box in Figure 10. There is no significant relationship between the fisheye size of carburizing and nitriding specimens and the fatigue life, as shown in Figure 11. The defect leading to internal failure is considered to be the largest defect of the fracture surface. If it is regarded as a random variable, they are independent and can be represented by the same cumulative distribution function. Assume that the maximum defect size of each fracture surface obeys the Gumbel distribution, Weibull distribution and GEV distribution, and its probability distribution function $F(\mathrm{x})$ is shown as follows:

$$
\begin{gathered}
\text { Gumbel: } F(X)=\exp \{-\exp [-(x-\lambda) / \alpha]\} \\
\text { Weibull: } F(X)=1-\exp \left[1-(x / \beta)^{\xi}\right] \\
\text { GEV: } \left.F(X)=\exp \{-[1+\eta(x-\lambda) / \alpha)]^{-1 / \eta}\right\}
\end{gathered}
$$

where $\alpha$ and $\beta$ are scale parameters, $\lambda$ is location parameter, $\zeta$ and $\eta$ are shape parameters.

Sort the size of defects in order from small to large. Let $x_{\mathrm{i}}$ be the size of the ith defect, $i=1,2,3, \ldots ., n$, where $n$ is the total number of defects. Based on the average rank formula, the cumulative probability function corresponding to $x_{\mathrm{i}}$ is expressed as follows:

$$
F\left(X_{i}\right)=\frac{i}{n+1}
$$

Based on Eq. (8), the parameter values of the three distribution functions were obtained by combining the graph estimation method and numerical calculation method, as shown in Table 2. The distribution curve of defect size is shown in Figure 12-14.

Table 2. Parameter values of probability distribution function

\begin{tabular}{cccccccc}
\hline $\begin{array}{c}\text { Distribution } \\
\text { type }\end{array}$ & \multicolumn{2}{c}{$\begin{array}{c}\text { Gumbel } \\
\text { distribution }\end{array}$} & \multicolumn{2}{c}{$\begin{array}{c}\text { Weibull } \\
\text { distribution }\end{array}$} & \multicolumn{3}{c}{ GEVdistribution } \\
\hline Parameter & $\alpha$ & $\lambda$ & $\zeta$ & $\beta$ & $\lambda$ & $\eta$ & $\alpha$ \\
NS & 26.37 & 27.27 & 1.44 & 45.60 & 22.20 & -1.594 & 116.3 \\
CS & 9.69 & 23.2 & 3.17 & 32.33 & 31.224 & -1 & 8.931 \\
\hline
\end{tabular}

Table 3. Maximum defect size under given probability

\begin{tabular}{ccccccc}
\hline $\begin{array}{c}\text { Distribution } \\
\text { type }\end{array}$ & \multicolumn{2}{c}{$\begin{array}{c}\text { Gumbel } \\
\text { distribution }\end{array}$} & \multicolumn{2}{c}{$\begin{array}{c}\text { Weibull } \\
\text { distribution }\end{array}$} & \multicolumn{2}{c}{$\begin{array}{c}\text { GEV } \\
\text { distribution }\end{array}$} \\
\hline Failure & $95 \%$ & $99 \%$ & $95 \%$ & $99 \%$ & $95 \%$ & $99 \%$ \\
probability & 105.60 & 148.58 & 97.69 & 131.69 & 94.49 & 95.08 \\
Inclusion size & 51.98 & 67.77 & 30.6 & 47.04 & 39.70 & 40.07 \\
$(\mathrm{NS}) / \mu \mathrm{m}$ & & & & & &
\end{tabular}

Inclusion size

(CS) $/ \mu \mathrm{m}$

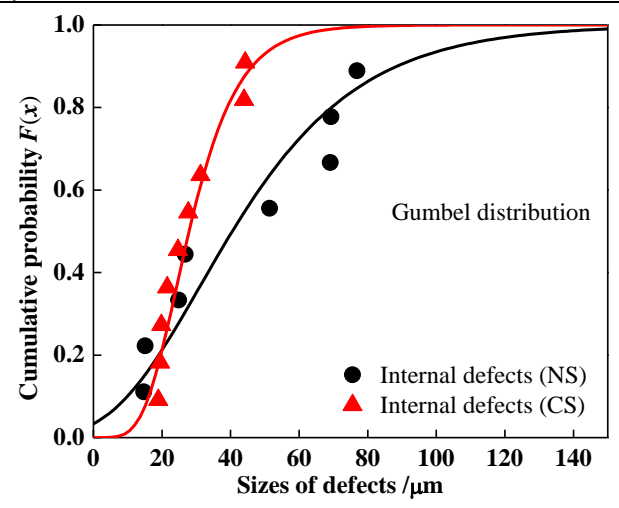

Figure 12. Gumbel distribution of defects size

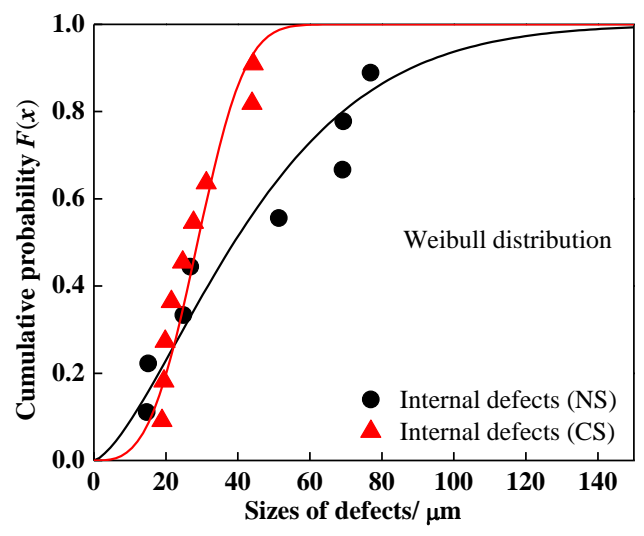

Figure 13. Weibull distribution of defects size 


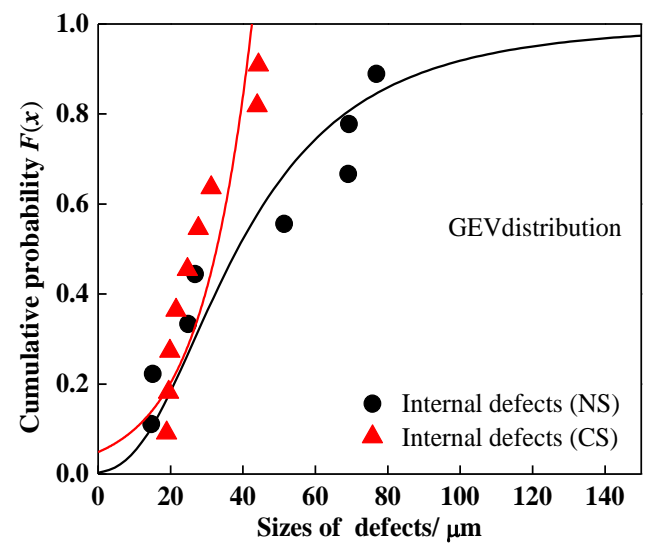

Figure 14. GEV distribution of defects size

According to Figures 12-14, it can be found that the defect size distribution curves predicted by the three distribution functions are all consistent with the experimental data, the maximum defect size was calculated under the failure probability of $95 \%$ and $99 \%$ respectively, as shown in Table 3 . In the evaluation of the defect size of nitrided and carburized specimens, the predicted value of Gumbel distribution is the largest and the calculated defect size has a big difference with the change of probability. The predicted value of Gumbel distribution and Weibull distribution are small, and the difference of the predicted value is small when comparing the predicted results of the two.

\subsection{Modeling of interior damage}

The Tanaka-Akiniwa model proved to have the chief drawback is that it overestimates the inclusion size effect [24], so in this study, based on the model of Tanaka-Akiniwa [25], considering the influence of the relationship between FGA and the size of internal defects on fatigue strength, and the influence of FGA and size of internal defects was set as parameter $\beta$, that is $\beta=1-\left(\frac{\sqrt{\text { are } a_{\mathrm{def}}}}{\sqrt{\text { area }_{\mathrm{FGA}}}}\right)^{\frac{(m-2)}{2}}$. Based on Eqns. (2), (3) and (4), the following equation can be obtained:

$$
\begin{gathered}
\left(\Delta K_{\mathrm{def}}\right)^{m}\left(\frac{N_{\mathrm{f}}}{\sqrt{\text { area }_{\mathrm{def}}}}\right)=\frac{2}{C(m-2)} \beta \\
\sigma_{a}=2 \frac{\sqrt{\pi}}{\pi}\left[\beta \frac{2}{C(m-2)}\right]^{1 / m} N_{\mathrm{f}}^{(-1 / m)}\left(\sqrt{\text { area }_{\text {def }}}\right)^{(1 / m-1 / 2)}
\end{gathered}
$$

Combined with the research results of the relationship between FGA size and inclusion size obtained by Chapetti et al. [26]: $\frac{\sqrt{\text { area }_{\mathrm{FGA}}}}{\sqrt{\text { area }_{\mathrm{inc}}}}=0.25 N_{\mathrm{f}}^{0.125}$, and since the inclusion size is smaller than the FGA size, $\beta$ can be rewritten as: $\left(\frac{1}{0.25 N_{\mathrm{f}}^{0.125}}\right)^{m-2 / 2}$, then put into Eq. (10) to get the modified Akiniwa new model:

$$
\sigma_{a}=2 \frac{\sqrt{\pi}}{\pi}\left[\frac{2}{C(m-2)}\right]^{1 / m} N_{\mathrm{f}}^{(-1 / m)}\left(\sqrt{\operatorname{area~}_{\mathrm{def}}}\right)^{(1 / m-1 / 2)}\left(4 N_{\mathrm{f}}^{-0.125}\right)^{(m-2) / 2 m}
$$

The maximum internal defect size of the three distributions was calculated with $95 \%$ and $99 \%$ failure probability respectively, and S-N curve of the internal failure specimen was obtained by combining with Eq. (11), as shown in Figures 15 and 16 . It can be found that the $S-N$ curves predicted by the three distributions show a continuous decreasing trend, which is consistent with the changing trend of the experimental data. It also proves that under a certain stress amplitude, the fatigue life decreases with the increase of the size of internal defects. Only with the Gumbel and Weibull distributions of nitriding specimens under $99 \%$ failure probability, the predicted results are safe, and the predicted results under the other cases are more dangerous. For the carburized specimen, the results of the three distributions are all conservative under the probability of $99 \%$, and the fatigue strength predicted by GEV distribution is the largest, followed by Weibull distribution and Gumbel distribution. However, at 95\% probability, Weibull's prediction results are the largest and risky, GEV distribution is the second, and Gumbel distribution is the smallest.

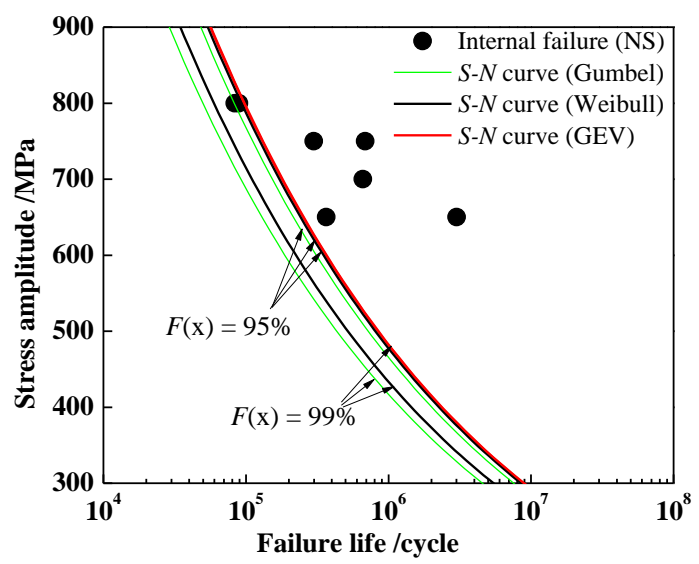

Figure 15. $S-N$ prediction curve of NS under given probability

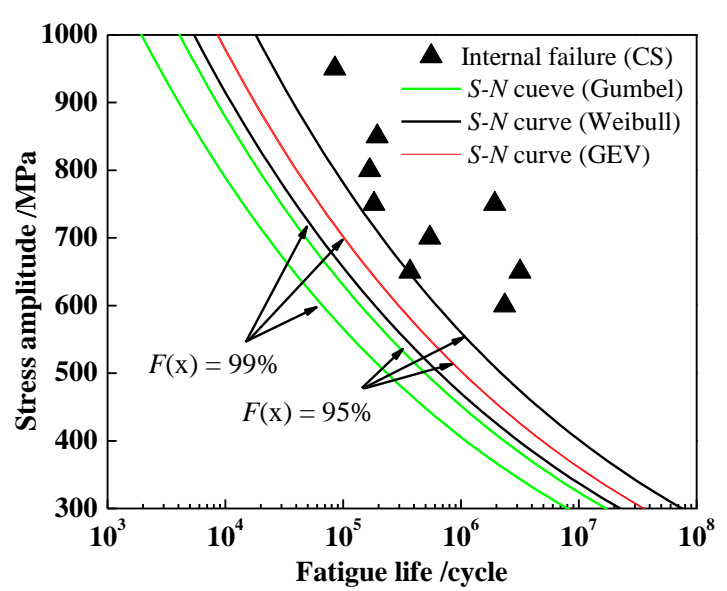

Figure 16. $S-N$ prediction curve of CS under given probability

\section{CONCLUSIONS}

The main conclusions obtained in this study are summarized as follows:

(1) Compared with untreated specimens, the surface failure fatigue strength of $18 \mathrm{Cr} 2 \mathrm{Ni} 4 \mathrm{WA}$ Steel increased by $13.5 \%$ and $21.6 \%$ respectively after nitriding and carburizing treatment. It is concluded that Carburizing treatment is better 
than nitriding treatment in improving the surface fatigue property of $18 \mathrm{Cr} 2 \mathrm{Ni} 4 \mathrm{WA}$ Steel.

(2) Both the carburized and nitriding specimens show a continuous decline of $S-N$ curve. In the range of very high cycle fatigue life, the internal failure caused by inclusion or IMA is the main failure mode of the $18 \mathrm{Cr} 2 \mathrm{Ni} 4 \mathrm{WA}$ steel, and the possibility of internal failure is increased. At low stress amplitude, the fatigue life of carburized and nitrided specimens is lower than that of untreated specimens, and the surface strengthening has a certain inhibition effect on the very high cycle fatigue life of the specimens.

(3) The maximum size range of internal defects of the nitriding specimen is larger than that of the carburizing specimen, and the effect of carburizing treatment is better than that of nitriding treatment in inhibiting the formation of large size defects in the specimen. The stress intensity factor of the nitriding specimen is greater than that of the carburizing specimen, which indicates that the effect of carburizing treatment on preventing crack propagation is better than that of the nitriding treatment

(4) A new cumulative damage model associated with the basis of Akiniwa model is proposed to predict the $18 \mathrm{Cr} 2 \mathrm{Ni} 4 \mathrm{WA}$ steel fatigue life with interior failure in the VHCF regime, the predicted value of GEV distribution is closer to the experimental value under the premise of safety than that of Gumbel distribution and Weibull distribution when the failure probability is $99 \%$.

\section{ACKNOWLEDGEMENT}

This research was supported by the National Natural Science Foundation of China (No. 51775043), the Natural Science Foundation of Hebei Province (No. E2018201265) and funded by Science and Technology Project of Hebei Education Department (No. QN2017307).

\section{REFERENCES}

[1] Li, N., Hong, Y., Wu, C.L., Xu, Q. (2018). Study on the gas nitrogen carbon co carburizing and subsequent quenching of low carbon steel. Surface Technology, 47(11): 9-16. https://doi.org/10.16490/j.cnki.issn.10013660.2018.11.002

[2] Ding, G.G., Sui, X.B., Liu, K.X., Chen, Z.W., Huang, Y., Jin, S.Z. (2020). Effect of Solution Nitriding on structure and properties of $\mathrm{Cr} 18 \mathrm{Mn} 21 \mathrm{Mo} 2.5$ steel. Surface Technology, 49(9): 324-331.

[3] Mao, S.M., Xu, X.L., Yu, Z.W. (2020). Microstructure and properties of plasma nitrided F51 duplex stainless steel. Surface Technology, 49(2): 185-191.

[4] Liu, J.R., Yan, H.Z., Li, S., Tian, H., Qin, J. (2019). Effect of plasma nitriding process parameters on surface microstructure and properties of $4 \mathrm{Cr} 5 \mathrm{MoSiV}$ steel. Surface Technology, 48(8): 199-205.

[5] Kikuchi, S., Yoshida, S., Ueno, A. (2019). Improvement of fatigue properties of Ti-6Al-4V alloy under four-point bending by low temperature nitriding. International Journal of Fatigue, 120: 134-140. https://doi.org/10.1016/j.ijfatigue.2018.11.005

[6] Gao, T., Sun, Z., Xue, H., Retraint, D. (2020). Effect of surface mechanical attrition treatment on high cycle and very high cycle fatigue of a 7075-T6 aluminium alloy.
International Journal of Fatigue, 139: 105798. https://doi.org/10.1016/j.ijfatigue.2020.105798

[7] Mayer, H., Schuller, R., Fitzka, M., Tran, D., Pennings, B. (2014). Very high cycle fatigue of nitrided $18 \mathrm{Ni}$ maraging steel sheet. International Journal of Fatigue, 64 140-146. https://doi.org/10.1016/j.ijfatigue.2014.02.003

[8] Jo, B., Sharifimehr, S., Shim, Y., Fatemi, A. (2017). Cyclic deformation and fatigue behavior of carburized automotive gear steel and predictions including multiaxial stress states. International Journal of Fatigue, 100: 454-465. https://doi.org/10.1016/j.ijfatigue.2016.12.023

[9] Sakai, T., Nakagawa, A., Oguma, N., Nakamura, Y., Ueno, A., Kikuchi, S., Sakaida, A. (2016). A review on fatigue fracture modes of structural metallic materials in very high cycle regime. International Journal of Fatigue, 93: 339-351.

https://doi.org/10.1016/j.ijfatigue.2016.05.029

[10] Ramlee, E.B., Hussain, P.B., Shaik, N.B. (2020). Enhancing the lifetime and corrosion resistance of gears made of carbon steel. Materialwissenschaft und Werkstofftechnik, 51(6): 774-779. https://doi.org/10.1002/mawe.201900254

[11] Sawicki, J., Siedlaczek, P., Staszczyk, A. (2018). Finiteelement analysis of residual stresses generated under nitriding process: a three-dimensional model. Metal Science and Heat Treatment, 59(11): 799-804. https://doi.org/10.1007/s11041-018-0229-y

[12] Limodin, N., Verreman, Y., Tarfa, T.N. (2003). Axial fatigue of a gas-nitrided quenched and tempered AISI 4140 steel: Effect of nitriding depth. Fatigue \& Fracture of Engineering Materials \& Structures, 26(9): 811-820. https://doi.org/10.1046/j.1460-2695.2003.00682.x

[13] Chen, Y.Y., Liu, Q.C., Liu, Z.Y., Gao, X., Xie, K., Sun, J.Q. (2018). Research on wear resistance of stator gear surface for transmission with carburizing and nitriding. Hot Working Technology, 47(4): 207-211

[14] Song, Y.N., Xu, B.S., Wang, H.D., Zhang, Y.B., Xing, Z.G. (2016). Life prediction models in very high cycle fatigue regime. Rare Metal Materials and Engineering, 45(5): 1203-1208

[15] Sun, C., Liu, X., Hong, Y. (2015). A two-parameter model to predict fatigue life of high-strength steels in a very high cycle fatigue regime. Acta Mechanica Sinica, 31(3): 383-391. https://doi.org/10.1007/s10409-0150451-4

[16] Xie, S.X., Li, J.K., Hou, F., Liu, Y.J., Wang, Q.Y., Zhang, J.H. (2016). Fatigue behavior of CrMoW rotor steel at elevated temperature in very high cycle regime. Journal of Material and Heat Treatment, 37(2): 77-83.

[17] Murakami, Y., Toriyama, T., Coudert, E. M. (1994). Instructions for a new method of inclusion rating and correlations with the fatigue limit. Journal of Testing and Evaluation, 22(4): 318-326. https://doi.org/10.1520/JTE11840J

[18] Weibull, W. (1951). A statistical distribution function of wide applicability. Journal of Applied Mechanics, 18(3): 293-297.

[19] Aitkin, M., Clayton, D. (1980). The fitting of exponential, Weibull and extreme value distributions to complex censored survival data using GLIM. Journal of the Royal Statistical Society: Series C (Applied Statistics), 29(2): 156-163. https://doi.org/10.2307/2986301

[20] Tanaka, K., Akiniwa, Y. (2002). Fatigue crack 
propagation behaviour derived from $\mathrm{S}-\mathrm{N}$ data in very high cycle regime. Fatigue \& Fracture of Engineering Materials \& Structures, 25(8-9): 775-784. https://doi.org/10.1046/j.1460-2695.2002.00547.x

[21] Akiniwa, Y., Miyamoto, N., Tsuru, H., Tanaka, K. (2006). Notch effect on fatigue strength reduction of bearing steel in the very high cycle regime. International Journal of $\quad$ Fatigue, 28(11): 1555-1565. https://doi.org/10.1016/j.ijfatigue.2005.04.017

[22] Sakai, T., Oguma, N., Morikawa, A. (2015). Microscopic and nanoscopic observations of metallurgical structures around inclusions at interior crack initiation site for a bearing steel in very high - cycle fatigue. Fatigue \& Fracture of Engineering Materials \& Structures, 38(11): 1305-1314. https://doi.org/10.1111/ffe.12344

[23] Sakai, T., Takeda, M., Tanaka, N., Kanemitsu, M., Oguma, N., Shiozawa, K. (2001). SN property and fractography of high carbon chromium bearing steel over ultra wide life region under rotating bending. Transactions of the Japan Society of Mechanical Engineers, Series A, 67(663): 1805-1812.

[24] Furuya, Y. (2019). A new model for predicting the gigacycle fatigue strength of high-strength steels. Materials Science and Engineering: A, 743: 445-452. https://doi.org/10.1016/j.msea.2018.11.109

[25] Akiniwa, Y., Miyamoto, N., Tsuru, H., Tanaka, K. (2006). Notch effect on fatigue strength reduction of bearing steel in the very high cycle regime. International Journal of Fatigue, 28(11): 1555-1565. https://doi.org/10.1016/j.ijfatigue.2005.04.017

[26] Chapetti, M.D., Tagawa, T., Miyata, T. (2003). Ultra-long cycle fatigue of high-strength carbon steels part II: estimation of fatigue limit for failure from internal inclusions. Materials Science and Engineering: A, 356(12): 236-244. https://doi.org/10.1016/S09215093(03)00136-9 